\title{
The effect of diet, temperature and diapause on the number and identification of larval instars in the oriental fruit moth Grapholita molesta (Busck) (Lepidoptera : Tortricidae)
}

\author{
D.A. Russel* and R. Bouzouane \\ INRA, Station de Zoologie et d'Apidologie, 84140 Montfavet, France
}

(received 10 December 1988; accepted 27 June 1989)

\begin{abstract}
Summary - It has been demonstrated that the Oriental fruit moth (Grapholita molesta) has 5 larval instars when reared on an artificial diet at various constant temperatures ranging from $11-28{ }^{\circ} \mathrm{C}$, on apple and on peach at $25^{\circ} \mathrm{C}$ and on an artificial diet and apple under field conditions. Instars may be distinguished by head capsule width on any one medium, but mean widths vary significantly between media. Insects feeding on peach shoots in the field in New Zealand and France showed only 4 larval instars. The distribution of head capsule widths from all the above experiments conform to Dyar's rule. Larvae feeding on peach fruit in the field showed a complex mixture of 4 and 5 instar forms, whereas larvae reared under diapause inducing photoperiods had consistently larger mean head capsule widths for a given instar than those reared under different conditions. Mean head capsule size increased slightly with rearing temperature to a maximum of $25^{\circ} \mathrm{C}$ then declined slightly to $28^{\circ} \mathrm{C}$. In addition to head capsule width, the colouration of body parts is used to provide a practical method of separating instars.
\end{abstract}

head capsule - development - apple - peach - shoot - fruit

Résumé - Effet du régime alimentaire, de la température et de la diapause sur le nombre et l'identification des stades larvaires de la tordeuse orientale du pêcher Grapholita molesta (Busck) (Lepidoptera : Tortricidae). On montre que la Tordeuse orientale du pêcher (Grapholita molesta) présente 5 stades larvaires lorsqu'elle est élevée sur milieu artificiel à différentes températures constantes de 11 à $28^{\circ} \mathrm{C}$, sur pomme et sur pêche à $25^{\circ} \mathrm{C}$ et sur milieu artificiel et pomme en verger. Les stades larvaires peuvent être distingués par la largeur des capsules céphaliques sur chaque milieu mais les moyennes des largeurs varient significativement selon les milieux. Les insectes se nourrissant sur pousses de pêchers en conditions naturelles en Nouvelle-Zélande et en France montrent seulement 4 stades larvaires, tandis que sur pêches, au verger, ils montrent un mélange d'individus à 4 et 5 stades larvaires. Les larves élevées sous une photopériode induisant la diapause ont une capsule céphalique moyenne régulièrement plus grosse pour un stade donné que les larves élevées dans d'autres conditions. La largeur moyenne de capsule céphalique augmente légèrement avec la température d'élevage jusqu'à atteindre un maximum à $25^{\circ} \mathrm{C}$. Outre la largeur de la capsule céphalique, la coloration des différentes parties du corps est utilisée pour établir une méthode pratique de séparation des stades larvaires.

capsule céphalique - développement - pomme - pêche - pousse - fruit

\section{INTRODUCTION}

The Oriental fruit moth (OFM) (Grapholita molesta (Busck)) is a key pest of stonefruit and sometimes pip fruit in many parts of the world. Confusion exists in the literature as to the number of larval instars of OFM and to the methods of distinguishing between them when insects are reared under different conditions of temperature, light regime and diet. Calendar and developmental day degree calculations, based on the perceived instar distribution of larvae collected in the field, are used by horticultural advisors and entomologists to calculate the "Present address : Overseas Development Natural Resources Institute, Pheromone Application Group, Chatham Maritime, Chatham, Kent, England
ME4. 
probable egg laying period, and thus control measures for succeeding OFM generations. These calculations require an accurate division of larvae into specific instars.

The number of larval instars is widely reported as 5 (Reichart \& Bodor, 1972) or as 4 or 5 (Peterson \& Haeussler, 1928; Besson \& Joly, 1976, Roberts et al., 1978, Yokoyama et al., 1987). These authors provide means and/or ranges for the larval head capsule widths of the various instars and both Besson \& Joly (1976) and Reichart \& Bodor (1972) describe head capsule and body colour for all instars. Substantial ambiguities come to light when examining these works.

The question of instar number is discussed here in an effort to clarify the situation with respect to the influence of temperature, diet and the diapause status of larvae on the number of larval instars and their head capsule sizes, so that the individual larvae can be readily classified with regard to instar. We did not, however, pursue the question of the effects of gender on larval characteristics as this was unlikely to be useful in the field.

The above aims were pursued by examining the number of larval instars at various constant temperatures in the laboratory and by comparing them with results from insects feeding under similar conditions, on artificial diets, on apple and on peach shoots and fruits in the field. Head capsule and body colour also varied throughout the instars and the use of these features is explored for the purposes of instar identification.

\section{METHODS}

\section{The insects}

In New Zealand, measurements were taken in a laboratory situation using insects reared on apple and on peach shoots in the field. In France, measurements were taken on insects reared on an artificial diet under controlled temperatures in the laboratory, and a comparison was made of larvae reared on artificial diet, apple and peach shoots and fruits in the field.

In New Zealand, the insects used were derived from a laboratory colony reared over 30 generations on apple thinnings at $25 \pm 2{ }^{\circ} \mathrm{C}$ (Russel, 1986). In France, insects were reared at the station de zoologie et d'apidologie at Montfavet for many years on an artificial diet of between $22-23^{\circ} \mathrm{C}$ using the method of Ivaldi-Sender (1974) and the rearing system devised for Codling moth (Laspeyresia pomonella L.) by Guennelon et al. (1981). Larvae were reared at 11, 15, $18,21,25$ and $28{ }^{\circ} \mathrm{C}$. Relative humidity was maintained at over $75 \%$ and the (non-diapause inducing) photoperiod was $17 \mathrm{~h}$ in New Zealand and $18 \mathrm{~h}$ in France. The quality of the laboratory reared insects in terms of fecundity, fertility, longevity and development rates is described in the case of New Zealand by Russel (1986). These insects compare favourably with figures for those parameters derived from the field.

\section{Field sites}

Measurements of field derived larvae in New Zealand were taken on material sampled weekly from both shoots and fruits of peach c.v. "Golden Queen" in a non-insecticide treated orchard and a nursery in the same area, in the Kumeu district of North Auckland, between 23 December 1983-23 February 1984 (the mean temperature over that period was $18.4^{\circ} \mathrm{C}$ taken from hourly recordings in a standard meteorological site $100 \mathrm{~m}$ from the orchard). In France, field measurements were taken on larvae collected weekly from peach var. "Redwing" shoots and fruits in a noninsecticide treated orchard on the Isle de Barthelasse, department of Vaucluse, during the period 20 May-11 August 1987. The mean temperature over that period, as measured using a continuous recording thermohydrograph within the orchard, was $16.6^{\circ} \mathrm{C}$. In addition, larvae hatching from egg sheets, produced in the laboratory colony, were placed on both apples var. "Granny Smith" and artificial diet, in gauze sided $(1000 \times 400 \times 400 \mathrm{~mm}$ ) cages wedged in the crotches of trees at $1 \mathrm{~m}$ above ground level, within the same orchard from 1 June-4 August (mean temperature $17.1^{\circ} \mathrm{C}$ ). The egg sheets were placed on the media every 3 days for a period of 2 weeks, in order to ensure a good mixture of larval ages. This was repeated 3 weeks later with fresh media. A fresh artificial diet together with apples was added, as food quality diminished with time. Larvae moved readily to the new foodstuff, and samples were taken at 6 stages over the 12-week period.

\section{Diapause}

The effect of diapause on the number of larval instars in OFM was studied under diapause induced light regimes (Dickson, 1949) using both larvae reared in the New Zealand colony (on apple, 10 hours light/14 hours dark, $25^{\circ} \mathrm{C}$ ) and the french colony (on an artificial diet, 12 hours light/12 hours dark 11, 15, 18, $21,25,28^{\circ} \mathrm{C}$ ).

\section{Larval measurements}

The head capsule colour and body colour of all larvae were noted and the head capsule widths measured to an accuracy of $\pm 12.5 \mu \mathrm{m}$ using a binocular microscope equipped with a micrometer eyepiece. Between 30-118 (mean 51.51) larvae from each instar were measured for temperature and light regime in the laboratory and between 25-256 (mean 78.3) larvae for each instar in the field trials; the smaller numbers referring to the earlier instars. Head capsule width may be taken as evidence of instar number, with the ratio of the widths in succeeding instars remaining fairly constant, following Dyar's (1890) rule (or more appropriately, Brook's rule (Crosby 1973)). By taking a plot of the logarithm of the head capsule width against the instar number, we should be able to produce a 
fairly straight line as long as no instars have been overlooked. This method has been criticised by Schmidt et al. (1977) and Frick \& Wilson (1981); however, the number of instars, and the magnitude of head capsule widths, were far more variable in the organisms studied by them than in the OFM study case.

Comparisons could then be made between: diapause and non-diapause larvae reared on artificial medium at 6 temperatures and at $25^{\circ} \mathrm{C}$ on apple;

Larvae reared under the same fluctuating conditions on apple, artificial diet and on peach shoots and fruits.

\section{RESULTS}

\section{Instar number and head capsule size}

There were no significant differences between the 1st instar head capsule means of any of the treatments and they are not considered further here (see Table I for mean and range) except for their inclusion in regressions.

\section{Effect of temperature}

\section{Constant temperatures}

Figure 1 shows the distribution of head capsule sizes at $95 \%$ confidence intervals and ranges for

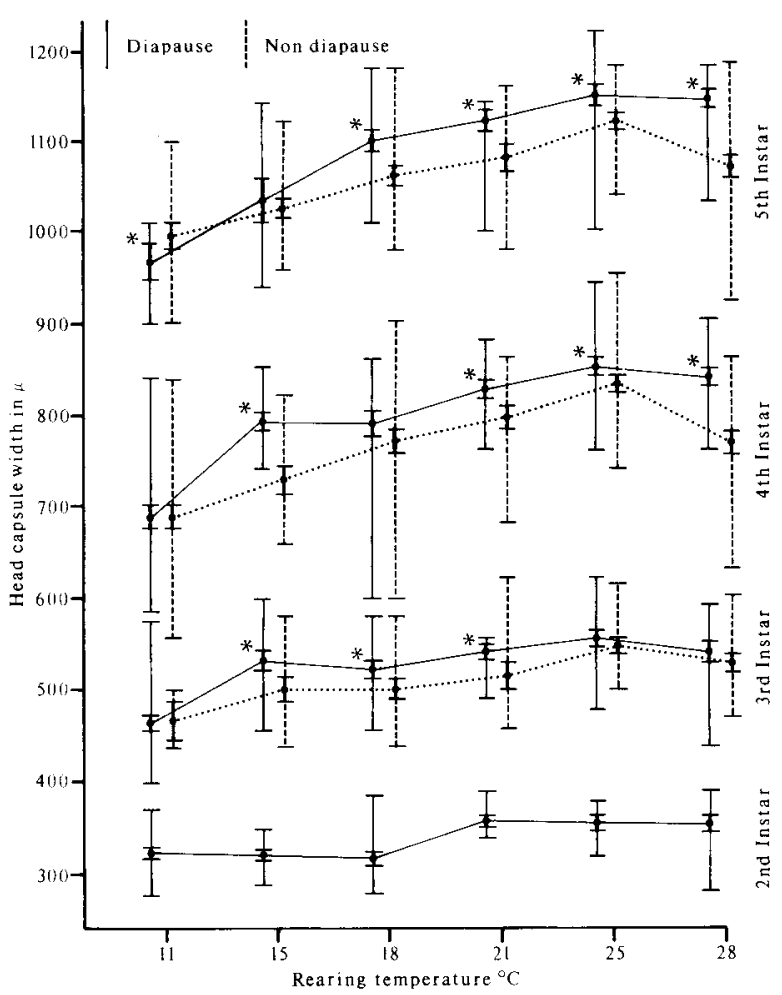

Fig. 1. Mean head capsule widths and $95 \%$ confidence intervals (solid bars) and ranges (in $\mu \mathrm{m}$ ) for head capsule widths of 2nd to 5 th instar larvae reared under diapause and non-diapause inducing photoperiods $(30<n<118$, mean 49.8). Asterisks indicate that the means for diapause and non-diapause larvae for a given instar and temperature are significantly different at $P<0.05$ using a one-way Anova.

Table I. Distinguishing characteristics for larval oriental fruit moth feeding on different media in both New Zealand and France. 5 instar form : artificial diet, apple and peach fruit in the laboratory and field. 4 instar form : peach shoots and fruits in the field. (Approximate mean head capsule widths and ranges in $\mu \mathrm{m}$.)

\section{Instar}
1
II
III
IV
$\checkmark$

\section{Instar form}

$\begin{array}{cccc}\text { Colour - Body } & \text { White } & \text { White } & \text { White } \\ \text { - Prothor. } & \text { Black } & \text { Black } & \text { Black } \\ \text { - Head Cap. } & \text { Black } & \text { Black } & \text { Black }\end{array}$

Head Cap. width -

$(190-250)$

350

(260-420)

520

$(400-680)$

\begin{tabular}{|c|c|c|c|c|}
\hline Colour & $\begin{array}{l}\text { - Body } \\
\text { - Prothor. } \\
\quad \text { shield } \\
\text { - Head Cap. }\end{array}$ & $\begin{array}{l}\text { White } \\
\text { Black } \\
\text { Black }\end{array}$ & $\begin{array}{l}\text { White } \\
\text { Black } \\
\text { Black }\end{array}$ & $\begin{array}{l}\text { White } \\
\text { Black } \\
\text { Black }\end{array}$ \\
\hline lead & ap. width - & $\begin{array}{c}225 \\
(190-250)\end{array}$ & $\begin{array}{c}360 \\
(300-440)\end{array}$ & $\begin{array}{c}620 \\
(460-760\end{array}$ \\
\hline
\end{tabular}

Head Cap. width -

4 Instar form

$\begin{array}{ll}\text { White } & \text { White to pink } \\ \text { Brown } & \text { Clear citrus } \\ \text { (occ. dark) } & - \text { yellow } \\ \text { Brown } & \text { Mottled honey } \\ \text { (occ. dark) } & \text { - brown }\end{array}$

780

(560-950)

1080

(900-1 260) 
diapause and non-diapause insects reared-under constant temperature on an artificial diet. Regression of the logarithm of mean head capsule width against instar gave values for $r^{2}$ (the proportion of the variation in mean head capsule width explained by the instar number) greater than 0.99 for the diapause and nondiapause rearing at all temperatures. The slopes of all lines lay between 0.39 and 0.42 . There is accordingly no evidence of "missing instars" in these data, which are based on an original division into instars of histogrammed data.

Five clear instars were present at all 6 temperatures; a one-way Anova showed significant differences $(P<0.05)$ amongst the mean head capsule widths at different temperatures for any given instar. There was a slight but regular change in mean head capsule size of each instar with temperature, reaching a maximum at $25{ }^{\circ} \mathrm{C}$ and showing a decline thereafter (Fig. 1). This was true for both diapause and non-diapause larvae. Within the 2 groups, the slopes of regression of mean head capsule widths on instar increased slightly but regularly with rearing temperature to maxima in the 2 highest rearing temperatures (diapause larvae : $b=0.376$ at $11^{\circ} \mathrm{C}, b=0.419$ at $28^{\circ} \mathrm{C}$, non-diapause larvae $b=0.385$ at $11^{\circ} \mathrm{C}, b=$ 0.414 at $25^{\circ} \mathrm{C}$ ). i.e. larvae were not only larger at higher temperatures but the difference was proportionally greater in later instars. Instar ranges at any given temperature were exclusive, but there were small overlaps when all the temperatures were considered collectively.

\section{Fluctuating temperatures}

Examination of the histogrammed mean head capsule widths in the field on artificial diet and apple also show 5 instars (artificial diet $r^{2}=$ $0.994, b=0.408$, apple $r^{2}=1.0, b=0.409$ (Fig. 2).

One may also compare the results for larvae reared on artificial diet and apple (c.v. "Granny Smith") in the field (fluctuating temperature mean for diet $16.6^{\circ} \mathrm{C}$, for apple $17.1^{\circ} \mathrm{C}$ ) and those reared in the laboratory $\left(25^{\circ} \mathrm{C}\right.$ ) (Fig. 2). The ranges of the head capsule widths under fluctuating conditions were contiguous or practically so for all 3 media, making clear divisions of instars of the basis of head capsule width alone difficult i.e. the head capsule widths under fluctuating temperature conditions were more variable than under constant temperature. In the field, and in particular on apple, where the variance in head capsule width is greater, the shape of the histograms nevertheless suggests exclusive ranges for the 2nd, 3rd and 4th instars

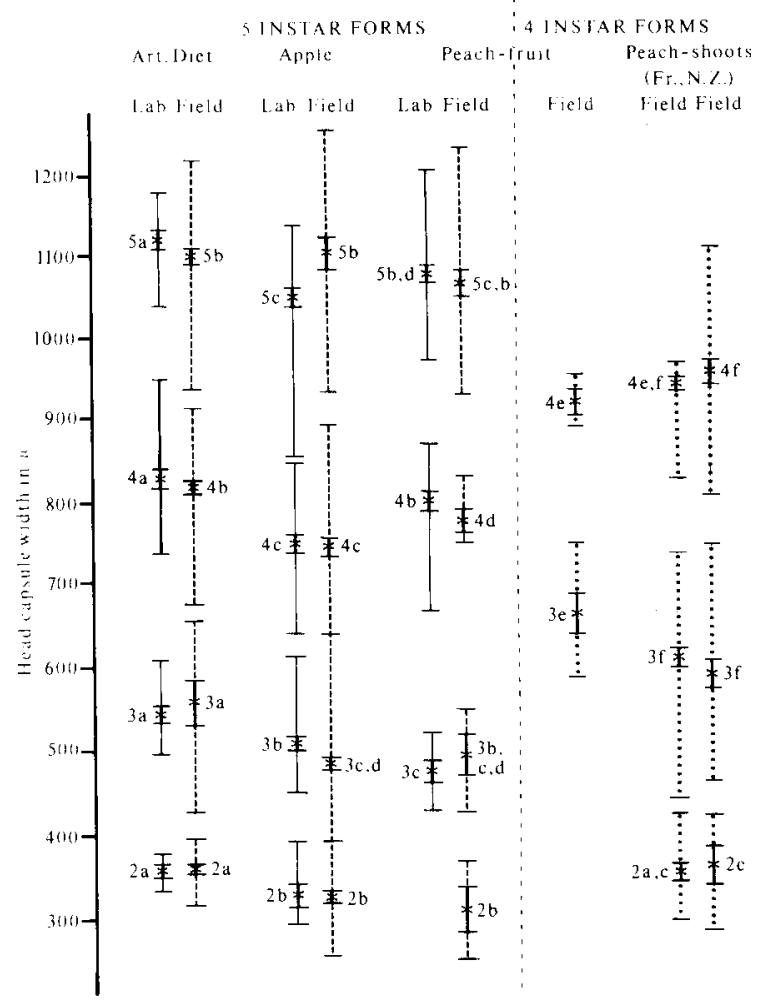

Fig. 2. Mean head capsule widths (asterisks) (with 95\% confidence interval (solid bars) and ranges) in $\mu$ for 2 nd and later instar larvae reared on artificial diet, apples and peach at $25^{\circ} \mathrm{C}$ in the laboratory (solid lines) and under fluctuating field (dotted lines) conditions (mean temp. ca. $17^{\circ} \mathrm{C}$ ). $(30<n<118$, mean 51.6). Means followed by the same number (instar) and letter are not significantly different at $P<0.05$ using a oneway Anova. *** (4 instar forms (all reared on peach).

(Fig. 2), with the 3rd to 4th instar division confirmed by changes in the colour of the hard parts from black to brown (see below). The timing of the appearance of the larger instars made it clear that a moult had occurred. The small $95 \%$ confidence intervals (Fig. 2) (owing in part to the large sample sizes), confirms this clear distinction between instars for most individuals.

Mean head capsule widths were not consistently larger at the higher mean rearing temperature. Comparing the constant temperature rearing data for the artificial diet at the nearest temperature $\left(18^{\circ} \mathrm{C}\right)$ also showed an irregular correlation even with the artificial diet rearing in the field i.e. there was probably a perturbing effect of fluctuating temperatures apart from the effect of the mean of those temperatures, perhaps acting on the larvae directly, or through changes in the quality of the diet.

We therefore concluded, from our data, that temperature, within the normal physiological range, has no apparent effect on instar number and only a slight effect on head capsule size. Any such effect of mean rearing temperature 
perse would not be readily discernible in populations in the field because of the increased variance in head capsule size in larvae reared under fluctuating field conditions.

\section{Effect of diet on instar number and head capsule size}

The means, 95\% confidence intervals and ranges for the head capsule widths of larvae reared at $25^{\circ} \mathrm{C}$ on artificial diet, apple C.v. "Granny Smith" and peach c.v. "Redwing" are compared in Figure 2. Regression of the mean head capsule widths against instar for the artificial diet gave $r^{2}=0.992$, and $b=0.414$, for peach $r^{2}=0.995, b=0.414$ and for the apple $r^{2}=0.999, b=0.382$ i.e. all had 5 clear instars with similar mean head capsule widths. Differences amongst the means of the 3rd, 4th and 5 th instars on the various rearing media in the laboratory were significant at $P<0.05$, with the artificial diet means largest but with no pattern present in the others. The head capsule widths of larvae, reared on the various media greatly overlap and this effect is relatively slight. Fig. 3a, b, c show these effects graphically. In the field, the variations around the means were such that there was no pattern for the difference between the means for any 1 instar for the 3 media (Fig. 2).

On the other hand, the data for larvae collected from peach shoots and fruits in the field

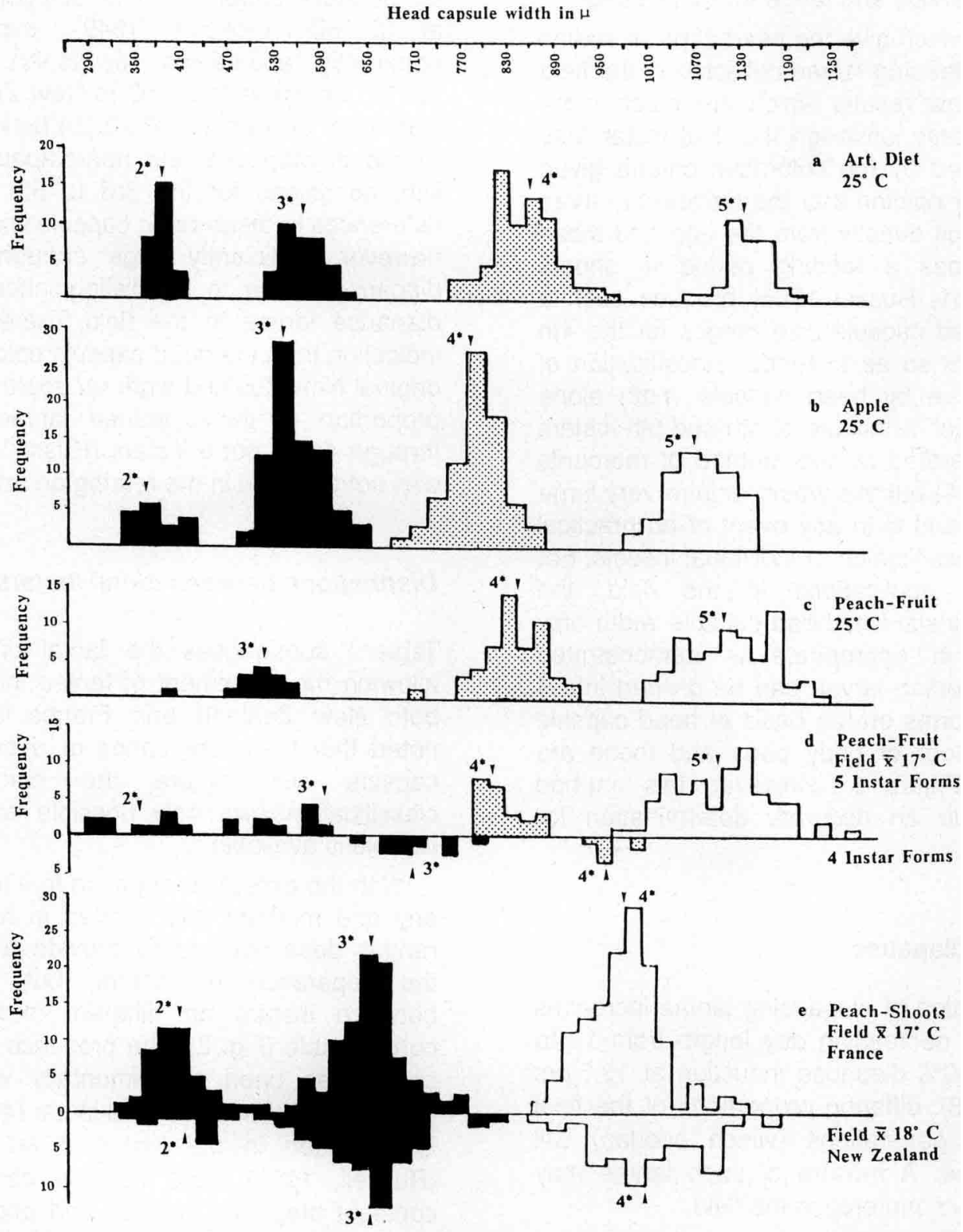

Fig. 3. Distribution of head capsule widths (in $\mu$ ) for larvae reared under non-diapause inducing light conditions on various media. Black - black head capsules and prothoracic shield. Dotted - brown head capsule and prothoracic shield. Clear - light brown head capsule and more or less clear prothoracic shield. Arrows indicate the mean for each instar. 
in France and in New Zealand show substantial differences from the above laboratory results. Instar divisions were made, on the basis of clear divisions between head capsule width classes in histogrammed data, and where necessary, taking body part colours (identified in laboratory work) into account.

Figure $3 e$ shows the distribution for head capsule sizes from larvae collected from shoots in New Zealand (c.v. "Golden Queen") and France (c.v. "Redwing"). A regression of mean head capsule width on instar number for the means of the 4 apparent instars gave $r^{2}=1.0$, $b=0.482$ for the N.Z. data and $r^{2}=0.988$, $b=0.499$ for the French results. It is apparent that the shoot feeding larvae develop through 4 instars only. (Fig. 2 presents the mean and 95\% confidence intervals and range for these larvae.)

Figure 3d, which give the head capsule widths of peach fruit feeding larvae collected in the field in France, show results which are much more difficult to classify, although the final instar may be distinguished by the coloration criteria given below. It is our opinion that the mixture of larvae which enter fruit directly from the egg and those which first pass a feeding period in shoots (Roehrich 1961; Russel 1986) produce such a mixture of head capsule size ranges for the 4th and 5th instars so as to render classification of individual larvae by head capsule width alone impossible. Such a mixture of 4th and 5 th instars might be separated by the method of moments (Pearson, 1894) but this would require very large sample sizes and is in any event of no practical use for the classification of individual insects. For most routine applications in the field, the separation of instars by head capsule width only is therefore in appropriate. As demonstrated below, fruit feeding larvae can be divided into 4 and 5 instar forms on the basis of head capsule width and colour of body parts and these are indicated in Figure 3. However, this method cannot provide an accurate determination for every larva.

\section{Influence of diapause}

As the proportion of diapausing larvae increases regularly with decreasing day length from 13 to $14 \mathrm{hrs}$, with $50 \%$ diapause induction at $13.5 \mathrm{hrs}$ (Russell, 1986), differing proportions of the final two summer generations (which overlap) will enter diapause. A mixture of such larvae may therefore be encountered in the field.

A comparison between larvae reared in nondiapause and diapause inducing light conditions for any given temperature (Fig. 1), showed that the differences between the means for the 3rd, 4th and 5th instars under the two light regimes was not always significant at $P=0.05$. There was no significant difference $(P>0.05)$ for the only comparisons available of the 1 st and 2 nd instars (on apple in New Zealand and artificial diet in France, both at $25^{\circ} \mathrm{C}$ ).

This lack of difference in the earlier instars may simply reflect the constraints imposed by the accuracy of measurement or may reflect the stage at which photoperiod has its maximum effect on diapause induction. However, with the exception of the results on artificial diet at $11^{\circ} \mathrm{C}$, the head capsule means for late instar diapause larvae are consistently larger than those for nondiapause larvae at the same temperature (Fig. 1). At $11^{\circ} \mathrm{C}$ there is an almost total low temperature suppression of diapause induction at 8L:16D (Dickson, 1949), explaining the apparently anomalous results. An experiment rearing on apple at $25^{\circ} \mathrm{C}$ in New Zealand gave significant differences $(P<0.05)$ between insects reared in diapause and non-diapause inducing light conditions for the 3rd to 5th instars. The differences in mean head capsule widths are not, however, sufficiently large enough to enable diapause larvae to be distinguished from nondiapause larvae in the field. There was some indication from the head capsule coloration in the original New Zealand work on apple that a small proportion of the diapause larvae developed through 4 and not 5 instars (Russell, 1986). This was not the case in the rearing on artificial diet.

\section{Distinctions between larval instars}

Table I summarises the larval characteristics allowing the placement of larvae into instars for both New Zealand and France. It should be noted that there are zones of overlap in head capsule size where the correct overall classifications are only possible when a large sample is available.

With the exception of peach fruit in the field on any one medium, the overlap in head capsule ranges does not usually provide a problem for the separation of instars, but the overlap between instars on different media may be considerable (Fig. 2). The presence of pink body colour has been experimentally verified as a reliable indicator of the final instar (4th or 5th) but is not seen in the instar at an early stage (Russell, 1986). Head capsule coloration is a constant black for the 1st, 2nd and 3rd instars and normally a light honey-brown for the final instar (4th or 5th). However, the 4th instar of 4 instar forms may have a dark, almost black, 
head capsule in certain circumstances (especially rearing on peach fruit) rather than the usual honey-brown. The 4th instar of 5 instar forms has a dull brown head capsule. Low rearing temperatures seem particularly conducive to the production of 4th and 5th instar larvae at the darker end of their respective ranges. However, the presence, in 5 instar forms, of a brown prothoracic shield nearly always distinguishes a 4th instar and that of a more or less clear prothoracic shield, a 5th instar. In 4 instar forms from peach shoots, the hard parts of the 4th instar are effectively coloured as are those of the fifth of a 5 instar distribution (a little darker in fruits), while the 2nd and 3rd instars show no change in coloration.

The head capsules of larvae reared under diapause inducing conditions are slightly larger in the 3rd, 4th and 5th instars than those reared in non-diapause inducing conditions but both are included in the overall instar range in Table $I$.

Figure 3d shows the 2 distributions for peach fruit feeding larvae divided on the basis of head capsule widths, body colour (pink = final instar, two forms) and head capsule and prothoracic shield colour (black $=2$ nd instar and 3rd instar (2 forms divided on head capsule widths), brown hard parts $=4$ th instar of 5 instar form, lighter head capsule and clearer prothoracic shield = final instar (two forms divided on depth of hard part colorations and the distribution of head capsule widths, both forms showing pink body colour)). These distributions for peach feeding larvae (and the mean figures calculated from them) are not necessarily precise but do indicate the presence of both 4 and 5 instar forms. The variation induced by all the above factors make it necessary to use Table I with caution, but instar divisions will normally be clear for any one rearing medium and set of environmental conditions.

\section{DISCUSSION}

The optimal temperature of $25^{\circ} \mathrm{C}$ found here for maximal head capsule widths agrees with the temperatures for maximal fecundity reported by Roehrich (1961) $\left(25^{\circ} \mathrm{C}\right)$ and Chaudhry (1956) $\left(24^{\circ} \mathrm{C}\right)$, but was not evident in the head capsule width data of Roberts et al. (1978).

The observed increase in the feeding period of larvae entering diapause (Helson, 1939; Dickson, 1949 ) is confirmed (Bouzouane \& Russell, in preparation) with the diapause larvae reaching larger head capsule sizes. Our data may also show that the effects of diapause inducing photoperiods can be seen in all instars after the second. This may imply that a major part of the inductive effect of the photoperiod is in the egg or early larval stages but the alimentary habits of OFM with respect to light have not been studied. If larvae prefer to feed in the dark, then this fact alone could explain the larger head capsule sizes in larvae destined to enter into diapause.

The temperature effect on head capsule size seen here confirms the observation of Roberts et al. (1978) that larvae at their lowest temperature $\left(15^{\circ} \mathrm{C}\right)$ were on average smaller than at higher temperatures, but suggests that the effect is consistent and not simply an artifact of the higher proportion of measurement taken immediately after moulting (when head capsule width is at a maximum) at the higher temperatures.

The measurements of four and five instar forms agree largely with the results of Yokoyama et al. (1987), who recorded 5 instars when reared at $26.8{ }^{\circ} \mathrm{C}$ on artificial diet and with those of Peterson \& Haeussler (1928) and Roberts et al. (1978), although the conditions producing the 2 forms appear to differ. Peterson \& Haeussler (1928) recorded both 4 and 5 instar generations on fruits of both apple and peach. In one series of trials when rearing took place over the same period, the peach feeding group developed more rapidly and had 4 instars while the apple feeding group had 5. However, in another series, both groups developed through 4 instars and in another both developed through 5 instars. They concluded that, in general, faster developing larvae (whether due to rearing temperature or host material) had a greater tendency to develop over 4 instars, although their data are variable and the results are not clear-cut. Roberts et al. (1978) rearing under constant temperature, found the reverse. At the highest rearing temperature, $30^{\circ} \mathrm{C}$, development was more rapid and there were a substantial proportion of larvae which developed through 5 instars. At $24^{\circ} \mathrm{C}$ there was some evidence of a small number of larvae developing through 5 instars, while at $20,17.5$ and $15{ }^{\circ} \mathrm{C}$ all larvae developed through 4 instars.

It was found that only diet (possibly through its effect on development rate) influenced the proportion of 4 instar forms. It would be interesting to examine the apparent dietary effect producing mainly 4 instar forms on apple thinnings in the rearing programme of Roberts et al. (1978) and 5 instar forms on apple c.v. "Granny Smith" in New Zealand and France.

Besson \& Joly (1976) described the head capsules of 4th instar OFM larvae as "brown" and that of 5th instar larvae as "clear brown", but did not make the distinction described here 
between the 4th instar of "4 instar" groups (regarded by those authors as occurring "sometimes in the first generation" and the 4th instar of " 5 instar" groups ("generally the case").

Reichart \& Bodor (1972) described the body colour of 4th and 5th instar larvae as "reddish" while Besson \& Joly (1976) describe the 4th instar as "grey to grey pink" and the 5th instar as "pink". According to our data, pinkish colouration is only characteristic of the final instar. The measured size range of head capsules for the 4th and 5th instars (showing reddish colouring) covered 728-1 $120 \mu \mathrm{m}$ for Besson \& Joly (1976), and 616-1 $120 \mu \mathrm{m}$ for Reichart \& Bodor (1972). The 4th instar range of Reichart \& Bodor (1972) covers much of that of the 3rd instar of other authors. It is possible that Besson \& Joly (1976) and Reichart \& Bodor (1972) were dealing with mixed populations of 4 and 5 instar forms (especially given that Besson \& Joly describe the 4th instar as "grey to grey-pink") but it seems remarkable, if the present analysis is correct, that they did not encounter any white-bodied individuals in the 4 th instar size range of the 5 instar form.

\section{ACKNOWLEDGEMENTS}

We would like to thank C. Leblon for assistance in the orchards and $H$. Audemard and the referees for critical reading of earlier drafts of the manuscript. Rearing and other facilities were provided in Auckland by the Entomology Division, New Zealand Department of Scientific and Industrial Research and in France by the Station de Zoologie et d'Apidologie, Institut National de la Recherche Agronomique, Montfavet. This work was supported by DSIR Auckland Univ. Contract UV 3/32 and by a NZ France fellowship from the French Department of Foreign Affairs.

\section{REFERENCES}

Besson J. \& Joly E. (1976) La tordeuse orientale du pêcher. Prévision des attaques, le piégeage au moyen d'attractif sexuel de synthèse, causes d'insuccès dans la lutte, proposition d'une stratégie de lutte. Rev. Zool. Agric. Pathol. Vég. 75, 1-22

Chaudhry G. (1956) The development and fecundity of the Oriental fruit moth Grapholitha (Cydia) molesta
(Busck) under controlled temperatures and humidities. Bull. Entomol. Res. 46, 869-98

Crosby T.K. (1973) Dyar's rule predated by Brook's rule. N.Z. Entomol. 5, 175-176

Dickson R.C. (1949) Factors governing the induction of diapause in Oriental fruit moth. Ann. Entomol. Soc. Am. 42, 511-537

Dyar H.R. (1890) The number of moults of lepidopterous larvae. Psyche 5, 420-422

Frick K.E. \& Wilson K.F. (1981) Head capsule measurements of Bactra verutina larvae reared on artificial diet. Environ. Entomol. 10, 237-239

Guennelon G., Audemard H., Fremond J. \& El Idrissi Ammari M. (1981) Progrès réalisés dans l'élevage permanent du carpocapse (Laspeyresia pomonella L.) sur milieu artificiel. Agronomie 1, 59-64

Helson G.A. (1939) The Oriental peach moth (Cydia molesta Busck). Investigations in the Goulburn Valley, Victoria. Progress report for 1935-1938. Counc. Sci. Indones. Res. Pam. 88

Ivaldi-Sender C. (1974) Techniques simples pour un élevage permanent de la tordeuse orientale, Grapholita molesta (Lepidoptera Tortricidae) sur un milieu artificiel. Ann. Zool. Ecol. Anim. 6, 337-343

Pearson K. (1894) Contributions to the mathematical theory of evolution. Philos. Trans. R. Soc. (A) 185, 71 110

Peterson A. \& Haeussler G.J. (1928) Some observations on the number of larval instars of the Oriental peach moth Laspeyresia molesta Busck. $J$. Econ. Entomol. 21, 843-852

Reichart G. \& Bodor J. (1972) Biology of the Oriental fruit moth (Grapholitha molesta Busck) in Hungary. Acta Phytopathol. Acad. Sci. Hung. 7, 279-295

Roberts W., Proctor J.R. \& Phillips J.H. (1978) Effects of constant temperatures on the number of larval instars of the Oriental fruit moth Grapholitha molesta (Lepidoptera : Tortricidae). Can. Entomol. 110, 623626

Roehrich R. (1961) Contribution à l'étude écologique des populations de la tordeuse du pêcher (Grapholitha molesta Busck) dans la région Aquitaine. Ann. Epiphyt. Ser C, 1-114

Russell D. (1986) The ecology of the Oriental fruit moth (Grapholita molesta Busck, Lepidoptera: Tortricidae) in New Zealand. Ph. D. Thesis, University of Auckland, New Zealand

Schmidt F.H., Campbell R.K. \& Trotter S. (1977) Errors in determining instar numbers through head capsule measurements in lepidopterans. A laboratory study and critique. Ann. Entomol. Soc. Am. 70, 750-756

Yokoyama V.Y., Miller G.T. \& Harvey J.M., (1987) Development of Oriental fruit moth (Lepidoptera : Tortricidae) on a laboratory diet. J. Econ. Entomol. 80, 272-276 